\title{
Mathematical modelling in science and mathematics education
}

\author{
Vítor Duarte Teodoro \& Rui Gomes Neves \\ Unidade de Investigação Educação e Desenvolvimento (UIED), Faculdade de \\ Ciências e Tecnologia, Universidade Nova de Lisboa (FCTUNL),Portugal \\ vdt@fct.unl.pt,rgn@fct.unl.pt
}

\begin{abstract}
Scientific research involves mathematical modelling in the context of an interactive balance between theory, experiment and computation. However, computational methods and tools are still far from being appropriately integrated in the high school and university curricula in science and mathematics. In this paper, it is discussed the relevance of mathematical modelling and illustrated how a computer modelling tool (Modellus, a free tool available on the Internet and developed at FCTUNL) can be used to embed modelling in high school and undergraduate courses. Modellus allows students to create and explore mathematical models using functions, differential and iterative equations, and visualize the behaviour of mathematical objects.
\end{abstract}

\section{The relevance of computer mathematical modelling}

Using computers as learning tools is becoming more and more common. There are many reasons for this, particularly those related to the fact that computers are a window to the networked world of information and knowledge. But in STEM subjects (Science, Technology, Engineering and Mathematics), and particularly in Physics, there are other reasons: computers are now an inevitable tool in the advancement of knowledge. Unfortunately, this is not yet true in most school curricula, where common practices still tend to reduce learning of STEM subjects to the rote accumulation of facts and rules, without emphasizing how knowledge and ideas are created and tested. Physics is a key subject in the science and technology education curricula. In spite of such central role, introductory physics continues to be extremely difficult for students both at the secondary and at the university level. Due to a lack of understanding of fundamental concepts in physics and mathematics, the number of students unable to pass on course examinations is usually very high. What is worse is that many of those students that eventually succeed also reveal several weaknesses in their understanding of elementary physics $[1,2]$.

Clearly, a solution for this problem requires changes in the processes by which science is taught and learnt. In recent years, many results of educational research have shown that the process of learning is effectively enhanced when students are involved in the learning 
activities as scientists are involved in research (e.g., [3]). Indeed, most scientific research is a dynamical process of creation, testing and improvement of mathematical models that describe observable physical phenomena (see, e.g., [4]). This process is an interactive blend of individual and group reflections based on a continuously evolving and mutually balanced set of theoretical, computational and experimental elements. It is from this cognitive frame of action that an inspiring understanding of the laws of the physical universe emerges. Hence, it should not be surprising that the process of learning science may turn out to be more successful in research inspired environments where students are helped to work as teams of scientists do. In this kind of class environment, knowledge performance is better promoted and common sense beliefs as well as incorrect scientific notions can be more effectively fought. In the scientific research process, computational modelling plays an important role in the expansion of the cognitive horizon through more powerful calculation, exploration and visualization capabilities. Consequently, modelling with computational methods and tools is also an important aspect of research inspired learning environments. In this context, it is crucial to achieve an early integration of scientific computation in a way that is balanced with theory and experiment. Only then the learning and teaching processes can be in phase with modern scientific research, where computation is as important as theory and experiment, and with the rapid parallel development of technology.

\section{Modellus and other computers tools for mathematical modelling}

Modelling in computer learning environments started with an emphasis on programming languages. Using, for example, Fortran [5], Pascal [6] and, more recently, Python [7], this approach requires students to develop a working knowledge of programming. The same happens with scientific computation software such as Mathematica or Matlab. To avoid overloading students with programming notions and syntax, computer modelling systems such as the Dynamic Modelling System [8], Stella [9], Easy Java Simulations [10] and Modellus [11] were developed to focus the learning activities on the understanding of the concepts of science and mathematics.

Our group has been involved in creating scientific software that young students can use, without the complexities of professional tools. Modellus, a mathematical modelling package freely available (http://modellus.fct.unl.pt) is a product of that effort and which is now an integral part of curricula, such as Advancing Physics, in the UK (http://advancingphysics.iop.org). Modellus allows students to create and explore models based on functions, differential equations and iterations and its interface is specially designed to be used without extensive training on how to use it. Modellus assumes that meaningful learning of abstract mathematical concepts, the key elements of scientific modelling, involves the reification of these concepts. The concepts of mathematics must be treated as real objects, as "objects-to-think-with", as Seymour Papert [12] wrote many years ago. And scientific software like Modellus allows students to treat mathematical objects as "concrete-abstract objects": concrete in the sense they can be manipulated and visualized and abstract because they are mathematical constructs. School curricula in STEM subjects, where computers are an integral part of the curricula, will, sooner or later, naturally incorporate modelling tools. This is not an easy task and the effort involved to make it will 
surely be long since it involves the development of new ideas, new curricular materials, professional development for teachers, dissemination of computers on school systems, changes in initial teacher education, etc. It is a difficult and long task, but it not an impossible one, and certainly it will be accomplished as school systems and society increase the use of computers and computer networks on all aspects of the emergent "information society".

Fig. 1 shows an example of a Modellus file for exploring simple harmonic motion using functions. The user can see the mathematical model, graphs and tables, change parameters, explore different cases (i.e., different sets of parameters), etc. As shown, the syntax of the model is exactly as it would be if it was written as an equation on paper.

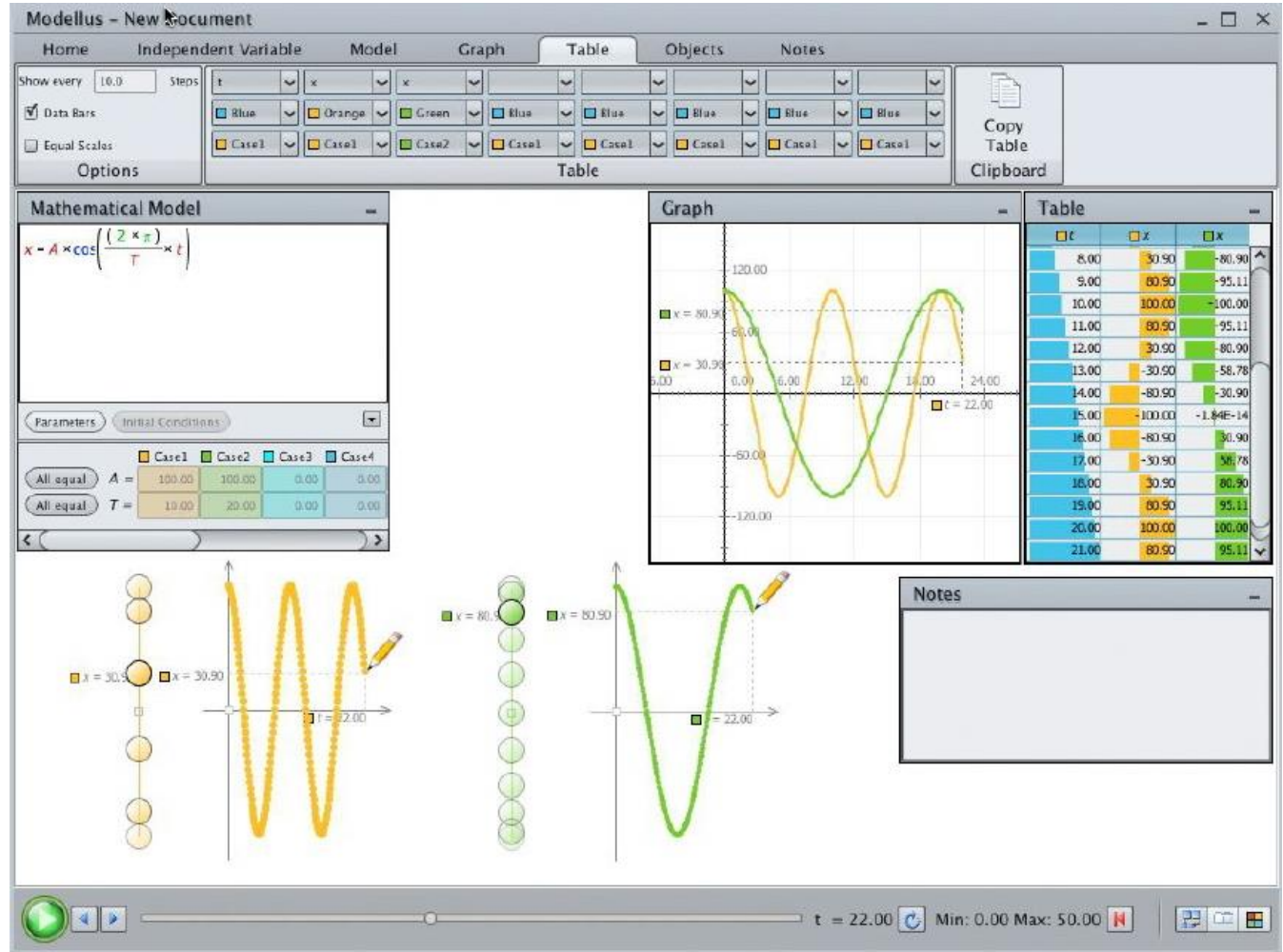

Fig. 1 A Modellus file illustrating simple harmonic motion, using functions and two sets of different parameters. This model can also be made using differential equations or iterative equations.

\section{Using Modellus with high school and undergraduate students}

In spite of important advances, a proper integration of computation with theory and experiment in science curricula and learning environments has not yet been achieved. Recently, we have started the development of an integration program at FCTUNL by 
implementing a set of activities based on computational modelling with Modellus in the general physics course [13-17]. These activities were successful in identifying and resolving several student difficulties in key physical and mathematical concepts of the course. Of fundamental importance to achieve this was the possibility to have a real time visible correspondence between the animations with interactive objects and the object's mathematical properties defined in the model, and also the possibility of manipulating simultaneously several different representations. In general, students reacted positively to the new component of the course, showing clear preference for interactive and exploratory group work. For the students, Modellus was seen as helpful and user friendly in the learning process of mathematical and physical models. The computational modelling activities with Modellus presented in PDF format with embedded video guidance were also considered to be interesting and well designed. Although in class the implementation of the computational activities was successful, we have noted a clear sense of caution and resistance to novelty, mainly because for students it meant extra work to master computational modelling besides just physics and mathematics. Students also felt that the content load was too heavy and that the available time spent on the computational modelling activities was insufficient. A similar degree of success was achieved with computational modelling activities involving elementary physics concepts applied to introductory meteorology, developed with Modellus for a meteorology course gathering students from undergraduate degrees in landscape architecture, environmental engineering, marine sciences and biology [18]. To improve the results of these field experiments, we are now studying in more detail the learning and teaching processes where computational methods and tools play an important role, and designing more compelling interactive digital documents.

\section{Acknowledgements}

Work partially supported by Unidade de Investigação Educação e Desenvolvimento (UIED) and Fundação para a Ciência e a Tecnologia (FCT), Programa Compromisso com a Ciência 2007.

\section{References}

[1] I. Halloun, D. Hestenes, The initial knowledge state of college physics students, American Journal of Physics 53 (1985) 1043-1048.

[2] L.C. McDermott, Milikan Lecture 1990: What we teach and what is learned-closing the gap, American Journal of Physics 59 (1991) 301-315.

[3] R. Beichner, L. Bernold, E. Burniston, P. Dail, R. Felder, J. Gastineau, M. Gjertsen, J. Risley, Case study of the physics component of an integrated curriculum, Physics Education Research. American Journal of Physics Supplement 67 (1999) 16-24.

[4] T. Crump, A Brief History of Science, As Seen Through the Development of Scientific Instruments, Robinson, London, UK, 2002. 
[5] A. Bork, Fortran for Physics, Addison-Wesley, Reading, Massachusetts, USA, 1967.

[6] E. Redish, J. Wilson, Student programming in the introductory physics course: M.U.P.P.E.T., American Journal of Physics 61 (1993) 222-232.

[7] R. Chabay, B. Sherwood, Computational physics in the introductory calculus based course, American Journal of Physics 76 (2008) 307-313.

[8] J. Ogborn, Dynamic Modelling System, Longman, Harlow, Essex, 1985.

[9] High Performance Systems, Stella, version 5, High Performance Systems, Hannover, NH, 1997.

[10] W. Christian, F. Esquembre, Modeling physics with Easy Java Simulations, The Physics Teacher 45 (8) (2007) 475-480.

[11] V.D. Teodoro, Modellus: learning physics with mathematical modelling, PhD Thesis, Lisboa, Faculdade de Ciências e Tecnologia, Universidade, Nova, de Lisboa, Portugal, 2002.

[12] S. Papert, Mindstorms: Children, Computers and Powerful Ideas, Basic Books, N.Y., 1980.

[13] V.D. Teodoro, Embedding modelling in the general physics course: rationale and tools, in: O. Slooten, E. van den Berg, T. Ellermeijer (Eds.), Proceedings of the International Group of Research on Physics Education 2006 Conference: Modelling in Physics and Physics Education, European Physical Society, Amsterdam, 2006, pp. 48-56.

[14] R.G. Neves, V.D. Teodoro, Computational modelling in science, technology, engineering and mathematics education, in: ICMI/ICIAM-Study on Educational Interfaces between Mathematics and Industry, Conference and Study Volume, Springer, 2010, in press.

[15] R. Neves, J. Silva, V. Teodoro, Computational modelling with Modellus: an enhancement vector for the general university physics course, in: A. Bilsel, M. Garip (Eds.), Frontiers in Science Education Research, Eastern Mediterranean University Press, Famagusta, Cyprus, 2009, pp. 461-470.

[16] R. Neves, J. Silva, V. Teodoro, Improving learning in science and mathematics with exploratory and interactive computational modelling, in: G. Kaiser, W. Blum, R. Borromeo Ferri, G. Stillman (Eds.), ICTMA14: Trends in Teaching and Learning of Mathematical Modelling, 2010, in press.

[17] R. Neves, J. Silva, V. Teodoro, Improving the general physics university course with computational modelling, Poster presented at the 2008 Gordon Research Conference, Physics Research and Education: Computation and Computer-Based Instruction, Bryan University, USA, 2008.

[18] R.G. Neves, M.C. Neves, V.D. Teodoro, Learning meteorology with computational modelling based on Modellus, Poster presented at the International Group of Research on Physics Education 2009 Conference (GIREP 09), University of Leicester, UK, 2009. 